Canadian Journal of Higher Education Revue canadienne d'enseignement supérieur

Volume 45, No. 4, 2015, pages 423 - 439

\title{
Assessing Mentoring Culture: Faculty and Staff Perceptions, Gaps, and Strengths
}

Lynn Sheridan, Natasha Hubbard Murdoch, \& Emily Harder Saskatchewan Polytechnic

\begin{abstract}
The purpose of this non-experimental, cross-sectional, descriptive research was to survey faculty and staff perceptions of mentorship in a postsecondary institution in order to determine gaps and strengths in the current mentorship environment. The anecdotal activities we present reflect our educational practice environment through the work of our Mentorship Team. Data were collected utilizing Zachary's Mentor Culture Audit tool. The culture building block measured 4.65 on a 7-point Likert scale, suggesting the presence of a weak mentorship culture. However, the infrastructure building block measured only 3.41, showing that organizational resources and supports are below average. We also present eight hallmark category results to further identify strengths and gaps. This is the first assessment of our mentoring culture at an organizational level. Other postsecondary institutions may benefit from formally assessing the gaps in and strengths of their mentorship culture to assist them with acquiring adequate resources to further develop and sustain their mentoring activities.
\end{abstract}




\section{Résumé}

Le but de cette recherche descriptive, non expérimentale et multidisciplinaire est de sonder le personnel et le corps professoral quant à ses perceptions du mentorat d'un établissement d'enseignement postsecondaire, afin de déterminer les lacunes et les points forts de leur programme. Les activités présentées reflètent le milieu de pratique professionnelle de notre équipe de mentorat. Les données ont été recueillies avec l'outil Zachary's Mentor Culture Audit. Le résultat de la culture de l'établissement était de 4,65 sur 7 selon l'échelle de Likert, suggérant une faible culture de mentorat. Toutefois, l'infrastructure institutionnelle mesurait à peine 3,41, démontrant que les ressources et le soutien organisationnels se situent au-dessous de la moyenne. On présente également les résultats de huit autres catégories d'importance pour identifier davantage les points forts et les lacunes. Il s'agit de notre première évaluation d'une culture de mentorat dans une organisation. D'autres établissements postsecondaires peuvent bénéficier de l'évaluation formelle de leurs programmes de mentorat afin d'aider à l'acquisition de ressources adéquates pour continuer à développer et à soutenir leurs activités de mentorat.

\section{Introduction}

This research team undertook a snapshot evaluation of mentorship in the health science programs in a postsecondary institution to validate the mentorship teamwork to date and gather data to focus strategic planning for future endeavours. The Mentoring Culture Audit tool was circulated to collect faculty and professional-services staff mentorship perceptions in two postsecondary health science divisions. Mentoring, as differentiated from coaching or role modelling, requires interaction between an experienced and a less-experienced person using formal and/or informal structures to attain personal and professional growth. Formal mentoring structures may be organizationally sanctioned, with supported activities, while informal mentoring relationships develop spontaneously between involved parties (Haynes \& Petrosko, 2009). Individuals who receive adequate mentoring have greater satisfaction in the workplace and clearer direction for scholarly endeavours, while organizations benefit from enhanced retention and recruitment; these effects culminate in a richer learning environment for students.

Zachary's (2005) framework was utilized to assess activities of the Mentorship Team, allowing for "diagnosing, analyzing, and prioritizing where the organization can best focus its time and effort in creating a mentoring culture" (p. 266). Focusing a finite amount of resources strategically can assist any organization in enhancing strengths and mitigating gaps in mentoring programs. This article begins with background information on mentoring and mentoring culture assessments, as a stepping stone to comprehending the study's results. We articulate the research questions in the second section, then describe our methodology in the third. The fourth section, on findings, includes a description of Zachary's building blocks and hallmarks, as well as anecdotal mentoring activities within the research practice environment, to assist in portraying the meaning of this study's results. The fifth section covers reliability and other measures. The discussion in section six is followed by concluding statements. 


\section{Background}

A search of multiple databases across business, education, and health, using the expanded concepts of mentor*, cultur* and eval*, found limited research on the organizational or aggregate levels of evaluating mentoring culture. The most fruitful results from this literature review arose out of hand searches of article reference lists.

In a review of mentoring programs, Zellers, Howard, and Barcic (2008) identified effective programs for higher education institutions seeking to foster an academic culture while respecting the professional development needs of faculty. Mentoring culture was dependent on context, which underpinned programs and reflected differences, thereby limiting comparison among the seven studies reviewed. A list of success factors for these mentoring programs included: visibility of leaders; alignment of personal, professional, and organizational goals; and availability of resources-all of which related to organizational culture. Wanberg, Welsh, and Hezlett's (2003) review of empirical research set the stage for understanding the scope of mentor program evaluation. They found that most research focused on outcomes for mentees rather than for mentors or organizations. The majority of research reported on informal or formal relationships and factors, such as increased job satisfaction, but were limited in validity for what was attributed to mentoring. Despite the assertion that formal mentoring programs had the potential to be management- or leadership-development tools for organizations, research actually focused on how well a given program socialized new employees to the business. Wanberg and colleagues suggested that evaluation should be at an aggregate level that includes all stakeholders to better understand the net outcome. They discussed how formal mentoring programs are enhanced by an organizational culture that supports continuous learning and values mentoring; they also proposed that mentoring should communicate those values through supervisor supports, development opportunities, and appropriate compensation. The authors found no research that addressed mentoring culture evaluated at an organizational aggregate level.

The majority of empirical research located during the present search was at a microlevel of program evaluation, looking at what supports for mentorship existed within the studied organizations. Johnson, Williams, and Jayadevappa (1999) found socialization in academic mentorship to be beneficial for minority faculty moving toward leadership positions. Mentoring circles with a focus on content experts supported junior tenure-track librarians in a case study of socializing to the expectations of one organization and its culture (Bosch, Ramachandran, Luevano, \& Wakiji, 2010). A formal mentor development program was evaluated through online surveys for clinical translational science faculty, and the results revealed increased confidence in mentoring skills focused around writing research grants (Feldman et al., 2012). Nurses in a bone marrow transplant program in Phoenix, Arizona, were supported through a five-step professional development model, which included a mentorship program supporting nurses striving for oncology certification (Marble, 2009). Marble (2009) revealed a minimum 20\% increase in certification success because of mentorship, stating, "the increased availability of expert nurses has had a positive impact on patient care and staff satisfaction" (Marble, p. 34). Mentor trust was measured in a sample of 140 dyads voluntarily enrolled in a two-year formal mentoring program in a Chinese industrial organization. The study's results showed that partici- 
pants who interacted professionally and socially developed trust and showed enhanced performance (Wang, Tomlinson, \& Noe, 2010). Finally, Palermo, Hughes, and McCall (2010) qualitatively evaluated a mentoring circle program's impact on competency development in public health nutritionists. Participants particularly appreciated learning within the workplace, which related back to the "process, structure, and functioning" of this particular program.

One study evaluated both the mentor/mentee relationship expectations and the structure of a mentor development program for 46 funded Clinical Translational Science Awards (Silet, Asquith, \& Fleming, 2010). The goal of the awards was to support the development of new scholars. The findings revealed a variety of mentor/mentee supports and varying progression towards formal evaluation of mentorship. However, senior faculty were sometimes sceptical about supporting the mentorship of junior researchers, as the former had been able to succeed without such supports-a finding that spoke to both the supports and the gaps within the organizations studied. What all this empirical research revealed at the micro-level is that mentor/mentee satisfaction in their relationship is often being used to evaluate effectiveness of mentoring programs.

Two studies provided a somewhat mid-level assessment of mentoring programs. A five-year longitudinal study of 18 hospitals in the United States utilized seven survey instruments (Gatson Grindel, \& Hagerstrom, 2009). Four instruments evaluated the mentor/mentee relationship for registered nurses and new graduates. The remaining three could be argued to have assessed organizational supports for mentoring: intent to stay, job satisfaction, and confidence. However, high levels of attrition in both nurses and mentoring programs resulted in a lack of comparable data across organizations. The second study revealed that information on mentoring initiatives that extend past a specific program or department within an organization was limited (Bean, Lucas, \& Hyers, 2014); qualitative and quantitative customer satisfaction data collected in a college during the first four years of a faculty mentoring program indicated that both mentors and mentees felt positively about their relationships and experiences within the program.

A more macro-level assessment was revealed in research on mentoring for leadership development. Middlebrooks and Haberkorn (2009) stated that "the root of effective leadership lies in the relationship built between leaders and followers" (p. 8) and suggested that a mentor/mentee dyad is a preview of emergent leaders. The author cited Zachary's phases of mentoring as phases of leadership development. In a second study, Hale (2000) explored mentoring in two organizations through semi-structured interviews, and extrapolated the benefits to organizations as being: progression across organizational learning goals; career development; flatter communication structures, which may reduce conflicts; recruitment and retention; and skill development. Finally, a Delphi study compiled a list of mentor functions that were variable across the industry contexts of academia, business, and the military (Smith, Howard, \& Harrington, 2005). These authors' own literature review found that previously researched mentor functions were similar between academia and business, but the jargon was unique. The results of their Delphi study supported their hypothesis regarding the relative importance of mentor traits; however, their hypotheses that mentor traits and functions are organizationally idiosyncratic were either not or only partially supported. This is a significant statement, suggesting that a quantitatively derived organizational evaluation of mentoring could be used across organiza- 
tions (or, in our case, across divisions). Adequate organizational support can facilitate the development of a strong mentoring culture (Zachary, 2005) and increase individual and organizational benefits. We found no study that empirically evaluated an organizational mentoring culture.

A mentoring culture "encourages the practice of mentoring excellence by continuously creating readiness for mentoring within the organization, facilitating multiple mentoring opportunities, and building in support mechanisms to ensure individual and organizational mentoring success" (Zachary, 2010). Cultures may be revealed through employee perceptions that assess employees' alignment with the organization's values, strategic direction, policies and practices, resource allocation, and leadership priorities focused on mentorship (Zachary, 2005).

\section{Research Questions}

The aim of this study was to assess for a mentoring culture in the Nursing and Science and Health divisions of Saskatchewan Polytechnic, as perceived by faculty and professionalservices staff. Zachary's (2005) building block categories and hallmark subcategories were used as the measurement parameters. The following four research questions guided this study:

1. Is a mentorship culture perceived in this sample?

2. Does the organization support mentorship?

3. Is support provided for mentorship?

4. What gaps in support for mentorship exist?

Questions two and three are similar in nature. However, question two was included to evaluate organization-wide support, while question three looked at more localized departmental and division support.

\section{Methods}

This non-experimental, cross-sectional, descriptive study (Johnson, 2001) used Zachary's (2005) 50-item Mentoring Culture Audit tool to collect perceptions about and support for a mentoring culture. This was a good methodology, even though reliability and validity data for the Mentoring Culture Audit have not been reported previously, as the variables in this preliminary assessment of the population were non-manipulable (Johnson, 2001).

\section{Selection of Participants}

The survey population consisted of full-time, part-time, and casual faculty and professional-services employees in two divisions that, combined, delivered 27 programs to a first-year enrolment of more than 1,700 students across the province of Saskatchewan. Approximately 420 faculty and staff delivered the 10-month to four-year programs. A convenience sample of 72 participants $(n=72)$ began the survey, for a response rate of $17 \%$. By the $50^{\text {th }}$ question, the response rate had dropped to $11 \%$. In terms of the attrition pattern, missing data appear to be subject-level rather than item-level (Kneipp \& McIntosh, 2001), possibly due to survey fatigue. Available case analysis was performed, with no imputation or deletion of missing values (Fox-Wasylyshun \& El-Masri, 2005). 


\section{Procedures}

Ethics approval was obtained from the appropriate research ethics board. The researchers received permission from Dr. Lois Zachary to use the Mentoring Culture Audit. Participants were recruited through posters, faculty meetings, and an email originating from the respective deans' offices. The survey was administered online in winter term of the 2013 academic year. Study information was provided on the first screen, and consent was attained by participants clicking the "I accept" button to proceed to the survey.

All participants were asked for minimal demographic data that included years of organizational experience, age group (in 10-year intervals), division, particular program, and distinction of faculty or professional services. The survey questions requested answers on a 7 -point Likert-type scale $(1=$ strongly disagree, through to $7=$ strongly agree). The survey took approximately 30 minutes to complete.

\section{Findings and Interpretations}

Zachary's Mentoring Culture Audit provided the framework to assess organizational building blocks and cultural hallmarks, described later in this section along with information on the practice environments' Mentorship Team activities. Table 1 depicts the mean scores by subscale, while Table 2 depicts the mean scores of each question within each subscale. The results are reported here, then expanded upon in the "Discussion" section. We begin here with measures, including reliability. Smith, Howard, and Harrington (2005) observed that mentor traits and functions may not be organizationally idiosyncratic, suggesting that aggregation of evaluation may therefore be appropriate. However, the current data did not allow us to report on this matter, as the sample from the health science faculty and staff was limited compared to the sample from nursing.

Table 1.

Zachary's Mentoring Culture Audit: Descriptive Results

\begin{tabular}{lccc}
\hline Subscale & $n$ & Mean $( \pm \mathrm{SD})^{*}$ & Reliability (alpha) \\
\hline Culture (A) & 72 & $4.65( \pm 1.11)$ & .86 \\
Infrastructure (B) & 67 & $3.41( \pm 1.23)$ & .92 \\
Alignment (I) & 63 & $3.75( \pm 1.06)$ & .80 \\
Accountability (II) & 61 & $3.42( \pm 1.22)$ & .87 \\
Communication (III) & 54 & $3.58( \pm 1.17)$ & .88 \\
Value \& Visibility (IV) & 52 & $3.63( \pm 1.33)$ & .87 \\
Demand (V) & 52 & $3.79( \pm 0.90)$ & .70 \\
Multiple Mentoring Opportunities (VI) & 52 & $3.46( \pm 1.15)$ & .89 \\
Education \& Training (VII) & 51 & $3.10( \pm 1.34)$ & .94 \\
Safety Nets (VIII) & 51 & $3.54( \pm 1.00)$ & .80 \\
\hline
\end{tabular}

* Measured on a 7-point scale, with higher scores indicating higher levels of the measured subscale. 
Table 2.

Means and SD for Individual Questions of the Mentoring Culture Audit

\begin{tabular}{|c|c|c|c|c|c|c|c|}
\hline Survey Section & & $n$ & Mean $( \pm \mathrm{SD})^{*}$ & Survey Section & & $n$ & Mean $( \pm \mathrm{SD})^{*}$ \\
\hline \multirow[t]{5}{*}{ Culture (A) } & $\mathrm{q} 1$ & 72 & $5.35( \pm 1.44)$ & Value \& Visibility (IV) & q26 & 52 & $4.00( \pm 1.60)$ \\
\hline & $\mathrm{q} 2$ & 72 & $4.85( \pm 1.37)$ & & q27 & 52 & $3.56( \pm 1.56)$ \\
\hline & q3 & 72 & $4.49( \pm 1.40)$ & & q28 & 51 & $3 \cdot 39( \pm 1.63)$ \\
\hline & q4 & 72 & $4.39( \pm 1.46)$ & & q29 & 52 & $3.27( \pm 1.67)$ \\
\hline & q5 & 71 & $4.17( \pm 1.32)$ & & q30 & 51 & $3.94( \pm 1.68)$ \\
\hline \multirow[t]{5}{*}{ Infrastructure (B) } & q6 & 67 & $3.75( \pm 1.40)$ & Demand (V) & q31 & 52 & $3.85( \pm 1.14)$ \\
\hline & q7 & 67 & $3.36( \pm 1.37)$ & & q32 & 52 & $4.69( \pm 1.31)$ \\
\hline & q8 & 67 & $3.09( \pm 1.49)$ & & q33 & 52 & $3.17( \pm 1.51)$ \\
\hline & q9 & 67 & $3.69( \pm 1.45)$ & & q34 & 51 & $3.59( \pm 1.33)$ \\
\hline & q10 & 66 & $3.17( \pm 1.45)$ & & q35 & 51 & $3.67( \pm 1.34)$ \\
\hline \multirow[t]{5}{*}{ Alignment (I) } & q11 & 62 & $3 \cdot 39( \pm 1.45)$ & $\begin{array}{l}\text { Multiple Mentoring } \\
\text { Opportunities (VI) }\end{array}$ & q36 & 51 & $3 \cdot 37( \pm 1.40)$ \\
\hline & $\mathrm{q} 12$ & 61 & $3.79( \pm 1.31)$ & & q37 & 51 & $3.57( \pm 1.29)$ \\
\hline & q13 & 63 & $3.49( \pm 1.26)$ & & q38 & 52 & $3.06( \pm 1.41)$ \\
\hline & q14 & 62 & $4.02( \pm 1.31)$ & & q39 & 52 & $3.79( \pm 1.41)$ \\
\hline & q15 & 63 & $4.06( \pm 1.51)$ & & q40 & 52 & $3.54( \pm 1.35)$ \\
\hline \multirow[t]{5}{*}{ Accountability (II) } & q16 & 60 & $4.08( \pm 1.41)$ & $\begin{array}{l}\text { Education \& Training } \\
\text { (VII) }\end{array}$ & $\mathrm{q} 41$ & 51 & $3.00( \pm 1.44)$ \\
\hline & q17 & 61 & $3.51( \pm 1.43)$ & & $\mathrm{q} 42$ & 51 & $3.25( \pm 1.52)$ \\
\hline & q18 & 61 & $3.03( \pm 1.51)$ & & q43 & 51 & $3.00( \pm 1.47)$ \\
\hline & q19 & 61 & $3.33( \pm 1.55)$ & & q44 & 50 & $3.14( \pm 1.55)$ \\
\hline & q20 & 61 & $3.21( \pm 1.47)$ & & q45 & 50 & $3.18( \pm 1.48)$ \\
\hline \multirow[t]{5}{*}{ Communication (III) } & q21 & 54 & $3.54( \pm 1.53)$ & Safety nets (VIII) & $\mathrm{q} 46$ & 51 & $4.51( \pm 1.17)$ \\
\hline & $\mathrm{q} 22$ & 53 & $3.53( \pm 1.64)$ & & q47 & 50 & $3.56( \pm 1.18)$ \\
\hline & q23 & 53 & $3.40( \pm 1.42)$ & & $\mathrm{q} 48$ & 50 & $3.10( \pm 1.30)$ \\
\hline & $\mathrm{q} 24$ & 51 & $3.43( \pm 1.32)$ & & q49 & 49 & $3.35( \pm 1.41)$ \\
\hline & q25 & 53 & $4.13( \pm 1.08)$ & & q5o & 51 & $3.08( \pm 1.51)$ \\
\hline
\end{tabular}

* Measured on a 7-point scale, with higher scores indicating higher levels of the measured question. 


\section{Measures}

Two participants were aged $18-29,10$ were $30-39,17$ were $40-49$, and 22 were 50 or older. ANOVAs were calculated between the three largest age groups, and the mean subscale scored for no significant differences $(p<.05)$. Because years of employment was measured as a categorical variable, correlation with the mean subscale scores could not be determined. However, ANOVA indicated no significant differences in scores between years of employment groups: zero to four years $(n=16)$, five to nine years $(n=16)$, and more than 10 years $(n=19)$.

Utilizing George and Mallery's (2003) interpretation of internal consistency, Cronbach's $\alpha$ for each of the subscales (two building blocks and eight hallmarks of five questions each) indicates acceptable $(>.70)$ to excellent $(>.90)$ reliability (Table 2$)$. Two subscales-(i) infrastructure and (ii) education and training-revealed as of 0.92 and 0.94 , respectively. Researchers have suggested that a higher a may suggest redundancy (Streiner, 2003), which is possible for a survey with 50 questions. The striking result, an $\alpha$ of 0.70 for the Demand subscale, shows inconsistency in the respondents for this set of questions versus all others. Further research with this cohort is required to determine whether these inconsistent results are due to the plausibility of the questions, comprehensibility of the items, motivation of the cohort, or sensitivity to the questions (Fong, Ho, \& Lam, 2010). Variability of results from one question to another in this subscale suggests plausibility is the issue. In healthcare, all workers are expected to contribute in terms of mentorship, preceptorship, and teamwork. The higher score for mentoring opportunities in a career could include previous practice before these participants became second-career educators. As well, turnover in this institution is associated with faculty returning to industry, where, in contrast to the education environment, workers would expect mentoring on return to a practice. The lowest score of the positive buzz for mentoring in this postsecondary institution may be due to a carryover from industry to educational environments.

\section{Practice Environment}

The Mentorship Team has existed at Saskatchewan Polytechnic for almost a decade. The team's initiation was supported by faculty and management to assist new faculty transition and promote the Canadian Association of Schools of Nursing's (2013) interpretation of the Boyer scholarship model's pillars of application, discovery, integration, and teaching. The Mentorship Team considered Zachary's (2005) anchors of a mentoring culture-"learning, development, diversity, knowledge management, and leadership" (p. 28)-as a starting point to develop mentorship program elements, including mentor training. Zachary's framework includes two building blocks and eight hallmarks, described below; we have incorporated The Mentorship Team's past activities as exemplars in parallel with the survey results.

\section{Building Block Results}

Following a great deal of discussion, we postulated that survey participants not involved in The Mentorship Team may not have consistently understood questions that utilized the term "organization" to mean the larger organizational entity rather than their

respective division. For the following findings, the researchers determined that the build- 
ing blocks of culture and infrastructure refer to the larger organization and therefore relate to research question one and two, while survey results for the hallmarks reflected the division levels of the organization, research questions three and four. The mean was used as the leverage point between gap and support, which provided the basis for determining options to strengthen supports and fill gaps. The first research question asked whether a mentorship culture was perceived in this sample.

The first building block, culture, measures how consciously aligned the values and actions of mentoring are in the organization (Zachary, 2005). Multiple perspectives to connect culture with business goals and mentoring practices are measured. The Mentorship Team strives for diverse representation from students, professional-services staff, faculty, and management of varying programs, which encourages communication back to stakeholder groups and a wider perspective on what education opportunities the team can offer. Everyone is encouraged to suggest activities and to join the team. The survey results for the building block culture displayed a mean of 4.65. Specific questions on learning as a priority for leadership and the organization scored high, suggesting support for organization-wide values. Questions on culture supporting mentorship and on using best practice for adult learning scored lower, indicating a gap exists at the organizational level.

The second building block, infrastructure, measures: the flexibility of the organization; the competencies of employees; mentoring in human resources, financial management, and technology; utilization of knowledge; leadership; and adequate time allocation (Zachary, 2005). Because the direct supervisors were most aware of new faculty, they assigned partnerships at the beginning of academic years. A Blackboard mentoring relationship education program was created. The majority of the program is secure to ensure confidentiality between mentor/mentee pairs; however, all members are accommodated for non-confidential discussion of course concepts. Mentorship lunch-and-learn sessions are open invitation. The Mentorship Team results, such as this research, are presented provincially, nationally, and internationally.

Infrastructure was one of the lowest overall mean results, at 3.41. The questions within this scale provided answers to research question two on whether the organization supports a mentorship culture. Having the right people in place to support, manage, and coordinate mentoring efforts scored the highest, at 4.17, indicating mentor/mentee matching is happening, and support from mentors is available. The technology and knowledge resources score, at 3.69, reiterates the need to continue with the online mentoring program and the circulation of monthly articles. The mentoring leadership succession plan scored 3.36. Partners having time for mentoring had a mean of 3.09, suggesting variability in whether mentor/mentee pairs found time within their workload to build relationships. Adequate budget and financial commitment came through as 3.17. These lower means related to research question four, suggesting that gaps in support exist. We interpret lower mean results to indicate inadequate infrastructure to sustain a strong mentorship culture.

\section{Hallmark Results}

The hallmarks give more specific information on areas that can be utilized to strengthen the two building blocks. Ultimately, the division leaders are in charge of resources. The hallmarks identified variable levels of responses to research question three. Gaps, from research question four, were found in all eight hallmarks. 
The first hallmark, alignment, assesses whether the organization thrives on core values, has integrity, and promotes effective, consistent mentoring processes (Zachary, 2005). To meet this hallmark, The Mentorship Team revisited the terms of reference yearly at a face-to-face workshop with members from three cities. This annual strategic planning session ensured the philosophy of the group met the organizational mission and values. This hallmark produced a mean of 3.75. Organizational values scored 3.79 and strategic planning for sustaining alignment 3.49. Roles, responsibilities, and expectations scored the lowest, at 3.39, indicating a potential opportunity to be leveraged with the mentoring pairs. Mentoring alignment with business goals and strategies scored better, at 4.02, and linkage to leadership was 4.06. The latter two may have scored well because some team members are in management positions, which suggests a recognized visibility.

Hallmark two, accountability, is the articulation of expectations between the individual and the learning organization (Zachary, 2005). The Mentorship Team pairs and circles are encouraged to set SMART goals, clarify expectations, define roles and responsibilities, monitor progress, evaluate results, gather feedback, and formulate action goals. Accountability scored a mean of 3.42. The purpose, scope, and benefits of mentoring scored 4.08. This question may have scored higher because faculty and staff became aware of mentoring as a benefit in previous work experiences. Clearly defined goals resulted in a mean of 3.51. This is an interesting result, as the majority of health programs teach how to develop, implement, and evaluate SMART goals, and mentor/mentee pairs are encouraged to develop their own. Progress towards goals being monitored scored 3.03, which suggests that faculty and staff are unaware either of goals or of how they are being assessed, or both. Measuring results over time was 3.33, and timely process improvements scored 3.21. The difficulty with being accountable for timely improvements is that as faculty turnover continues, team commitment wanes. Despite excellent record keeping, communication, and expert representation on the committee, reporting and reconciling plans remains a lower priority for implementing mentorship initiatives.

Communication, hallmark three, focuses on gaining awareness and understanding, building acceptance and buy-in, and fostering a commitment to mentoring (Zachary, 2005). Zachary feels communication is "the catalyst for developing mentoring readiness, generating learning opportunities, and providing mentoring support within an organization" (2005, p. 137). The Mentorship Team developed multiple communication avenues and processes. Middle-management team members report to the division leadership team on initiatives and requests. The province-wide team meets quarterly and as needed. A universally accessible shared network drive stores mentorship documents and resources. The Blackboard mentoring program frees the mentor/mentee pair from geographical barriers. In an effort to keep mentorship at the forefront of conversation, evidence-based research is disseminated via information boards in high-traffic areas as well as synthesized articles emailed to faculty and staff each month. The mean for the communication hallmark was 3.58. Consistent timely and regular communications showed a mean of 3.54. Strategic communications was 3.53. Shared mentoring vocabulary scored 3.40 , while multiple venues of communication was 3.43. Lastly, communications sensitive to culture and diversity scored 4.13. The lower scores in this hallmark suggest the team's member-member and member-leader processes may be stronger than member-faculty. The higher score for culture and diversity suggests that the organization supports awareness, which is apparent in its Aboriginal student success and Newcomer to Canada programs. 
Hallmark four is value and visibility. Zachary (2005) describes value as an input and output mechanism that should be encouraged through reward and recognition, promoting additional mentorship activities. Individuals in leadership positions are expected to contribute to visibility by role modelling the desired organizational and mentorship culture. The Mentorship Team has presented at annual division meetings. Mentors and mentees receive participation certificates at faculty meetings each academic year. Mentorship week has been celebrated for the past two years. A mean of 3.63 was the hallmark score for value and visibility. Mean scores on individual questions ranged from 3.27 to 4.0o. Leaders perceived as mentoring role models and consistently creating positive value of the organization scored the highest. Scores below the mean average came from: senior management visibility; excellence in mentoring being recognized, rewarded, and celebrated; and practices being shared regularly in multiple forums.

Demand, hallmark five, measures impact through indicators showing that mentoring has credibility and momentum within all the components of infrastructure, with the other seven hallmarks supporting it (Zachary, 2005). Zachary identified factors that prevent $d e-$ mand from flourishing: lack of credibility; inconsistent leader support; lack of a coherent strategy; disengagement; lack of patience or inadequate time to buy in; and exclusion. In our practice environment, time for faculty to engage in mentoring activities is secondary to planning and delivering content-driven curricula. While faculty expect mentoring, and they volunteer to support new faculty, staff, and each other, formal mentoring opportunities are limited and have poor attendance. Faculty often sustain mentor/mentee relationships through email, as co-ordinating face-to-face meetings is inhibited by clinical and student contact time. Notably, faculty are seldom able to mentor another with a similar course load. The hallmark of demand scored 3.79. Scoring high at 4.69 was mentors and mentees engaging in multiple relationships throughout their career. Enthusiastic participation in relationships was 3.85, while partners meeting regularly scored 3.67. Positive buzz about mentorship was lowest, at 3.17, followed by requests for additional opportunities to increase their effectiveness, at 3.59.

The sixth hallmark, multiple mentoring opportunities, assesses the options available to affirm individual uniqueness in learning styles (Zachary, 2005). Zachary states, "A mentoring culture strengthens and supports mentoring in whatever form it appears, whether formal, informal or a blend of the two" (p. 188). While formal pairing, with a focus on mentoring, does exist in our practice environment, informal mentoring is more common. Many faculties focused their professional development on patient and family needs and learning that supported their teaching of health science students. The switch to a combination of classroom, clinical, and scholarly activities required a variety of mentors and approaches. Team-teaching opportunities were utilized, including orientation to specialty departments in health care settings. Faculty were encouraged to ask practicing health institution staff to mentor, prior to orienting students to the clinical area. Division program meetings encouraged sharing of process and outcomes in departments, such as student assignment development, marking templates, tracking forms for large student groups, and health agency communication for student placement. The results for multiple mentoring moments included a mean of 3.46, with a range from 3.07 to 3.79. Appropriate broad opportunities throughout the organization to meet diverse learning needs, along with multiple mentoring types being supported, scored the lowest. Coaching 
and availability of information for support scored 3.57. Organizational support for formal and informal mentoring was 3.79 , while innovative models of mentoring was at 3.54 . To maintain ongoing variety in opportunities requires time and co-ordination. This hallmark result reiterated a gap: a lack of adequate resources, including a paid co-ordinator.

Education and training, hallmark seven, is the process of planning specific to broad opportunities that provide for the integration and portability of learning, resulting in a more "confident, competent, and creative workforce" (Zachary, 2005, p. 218). Following Knowles' adult learning principles (Knowles, Horton, \& Swanson, 2011), The Mentorship Team delivers education on mentoring, and opportunities for sharing mentor/mentee pair success. Lunch-and-learn sessions were delivered as (i) didactic, (ii) interactive and participant driven, or (iii) competency-based assessments in computer labs. These opportunities met Zachary's requirement that "mentoring training is a planned learning experience (an event or series of sessions) that focuses specifically on development of mentoring awareness, understanding, knowledge, and skills" (p. 218). Faculty and staff were encouraged to suggest topics and delivery methods, ensuring learning opportunities were relevant. Education and training scored the lowest in all of the subscales in the survey, with a mean of 3.10. Mentoring briefings, education sessions, and next-step training, as well as just-intime coaching, scored 3.00. Individual mentoring training events and education were at 3.14, while having timely, relevant, and up-to-date education and training was 3.18. The best of this section was training and education for individuals at different mentoring readiness, with a mean of 3.25. All education and training is done by The Mentorship Team. Presentations have been done at the organization-wide department head meetings. Much of the training sessions and mentorship information is available electronically. There appeared to be a disconnect between what is available and what is being utilized.

The final hallmark, safety nets, encourages risk taking, provides support, and ultimately strengthens the mentoring culture by reducing barriers, thereby allowing a mentoring team to move forward (Zachary, 2005). Zachary's proactive approaches use the mentoring phases of preparing, negotiating, enabling, and coming to closure. One example of preparing is using learning contracts at the start of the relationship. Negotiating occurs as goals are met and/or revised. Relationships are enabled through professional development sessions and by time spent socializing before and after faculty meetings. Closure of the mentoring relationship is acknowledged with a certificate during faculty meetings, usually planned a few months in advance to assist the mentoring pair to plan for the discussion and evaluation of goals.

The final hallmark of safety nets scored a mean of 3.54. This section had the largest mean range. Confidentiality was highly regarded, at 4.51. The ability to address stumbling blocks and obstacles scored 3.56. Prioritizing time for mentoring, by both mentors and mentees, resulted in a mean of 3.35, identifying a gap in adequate time to take full advantage of the mentoring relationship. Anticipating challenges and assessing opportunities that affect implementation of sustainability scored 3.10; the sustainability of any program requires proper resources, including personnel. Finally, mentoring ownership, and management being well established, scored a low 3.08.

Utilization of Zachary's (2005) Mentor Culture Audit provided a snapshot assessment of the mentoring culture in this organization for two divisions. This completes the anecdotal examination of the mentorship activities in relation to subcategories of Zachary's framework. 


\section{Discussion}

Taking the mean as the leverage point between gap and support gave The Mentorship Team the opportunity to determine options, including more exposure and planned communication strategies. Although many of the building block and hallmark subscores fell below the 3.5 average mean, there is indication that participants were aware of all categories. Identifying specific gaps will help The Mentorship Team maximize its current resources and strategically plan requests for additional resource allocation.

Faculty and staff perceived that a mentorship culture existed in this practice environment, answering the first research question, as the culture building block was the highestscoring section-confirming that organizational learning is a priority and supported by leadership. Douglas (1997) stated that an evaluation of mentoring programs should assess process and outcomes, a suggestion corroborated by Wanberg, Welsh, and Hezlett (2003), as evidenced by their development of a conceptual model of formal mentoring that takes into account micro- to macro-level components: antecedents, through program outcomes, to organizational context. Feedback should be attained from participants and nonparticipants and should collect information on program goals such as recruitment and retention, skill development, and employee attitudes, in addition to assessing links to business strategy (Douglas, 1997).

Survey responses showed some organizational support for mentorship (research question two), with room for improvement. The mean score of 3.41 for the infrastructure building block suggests a lack of alignment between mentoring relationship goals and organizational goals. Douglas (1997) stated: "formalized initiatives that pertain to organizational goals tend to be more focused and of shorter duration than those that pertain to individual developmental needs" (p. 83). Her review revealed the main benefits (from an organizational perspective) of a mentorship program to be recruitment and retention, enhanced diversity, improved communication, succession planning, and organizational commitment, while the main drawbacks included lack of support, difficulty tying mentorship to other program initiatives, and difficulty obtaining resources. She also reported that program objectives could generally be split between focusing on organizational goals or developing member needs. When a mentorship program has adequate financial and human resources, it is better positioned to be effective and sustainable. As noted above, the current program in this practice environment does not have a paid co-ordinator. Team members are volunteers, with the primary goal being to support the development of faculty and staff, in addition to increasing full-time student contact hours and meeting the organization's expectations regarding participating in committees, serving the community and conducting research.

The Mentorship Team is also one of four scholarship teams created to meet organizational business plan strategies. Considering time, skills, and pressure, faculty and professional-services staff may feel torn between commitments to mentorship, interprofessional education, best teaching practice development, and healthcare informatics teams. The development of these scholarship teams directly ties their goals to a division business strategy. However, alignment may be superficial. Zachary (2005) identifies the need for alignment between mentorship program goals and organizational vision, mission, and strategic direction. Douglas (1997) states that "when formal programs are not part of larger devel- 
opmental strategies and are viewed as separate, distinct programs, they are less likely to benefit from the added support and reinforcement of a larger management-development strategy" (p. 93). The results of the present study will allow The Mentorship Team to work on connecting the development of individual faculty and professional-services staff to division goals as well as learning organization vision and strategic plan more comprehensively.

The final two research questions address what supports and gaps exist within the current mentorship culture. While all subscales for the hallmarks fell below the mean, suggesting that work can continue on supporting the hallmarks that exist, no hallmark was strikingly missing. The lowest hallmark was education and training, with a mean of 3.10 for the subscale. The focus of this hallmark is on broad opportunities, with the particular intent of advancing mentorship awareness and knowledge. While The Mentorship Team provides mentoring opportunities and professional development for individuals and pairs, learning outcomes may be too focused on relationship support rather than mentorship content: goals, benefits/risks, implementation, and evaluation.

\section{Conclusion}

This study utilized Zachary's (2005) Mentoring Culture Audit tool to assess the building blocks and hallmarks of a mentoring culture in two divisions at Saskatchewan Polytechnic. Opportunities for improvement exist in many of the subcategories but especially in the education and training hallmark, which anecdotal reports had identified as an area requiring increased resources. The Mentorship Team's work was validated through an above-average mean in the culture building block. The remainder of the subscales fell close to an average result. This validates past work and provides food for thought in strategically planning future endeavours. Reliability results indicate this is an appropriate measurement tool; however, additional research using this assessment method is required to further verify the reliability measures. Comparing the Mentoring Culture Audit tool to the past activities of The Mentorship Team provided us with background for future considerations, which include continued measurement of our practice environment mentorship culture so it may be viewed through an ever-widening lens, micro to macro, personal to organizational, as success requires effort at all levels.

\section{Acknowledgements}

The researchers gratefully acknowledge the support of the Institute of Nursing Scholarship for project funding, and of statistician Erwin Karreman.

\section{References}

Bean, N. M., Lucas, L., \& Hyers, L. L. (2014). Mentoring in higher education should be the norm to assure success: Lessons learned from faculty mentoring program, West Chester University, 2008-2011. Mentoring \& Tutoring: Partnership in Learning, 22(1), 56-73. doi:10.1080/13611267.2014.882606

Bosch, E. K., Ramachandran, H., Luevano, S., \& Wakiji, E. (2010). The resource team model: An innovative mentoring program for academic librarians. New Review of Academic Librarianship, 16(1), 57-74. doi:10.1080/13614530903584305 
Canadian Association of Schools of Nursing. (2013). Position statement. Scholarship among nursing faculty. Available from http://casn.ca/wp-content/uploads/2014/10/ ScholarshipinNursingNov2013ENFINALmm.pdf

Douglas, C. A. (1997). Formal mentoring programs in organizations: An annotated bibliography. Greensboro, NC: Center for Creative Leadership. Available from www. centerforcreativeleadership.com/leadership/pdf/research/FormalMentoringPrograms.pdf

Feldman, M. D., Steinauer, J. E., Khalili, M., Huang, L., Kahn, J. S., Lee, K. A., . . . Brown, J. S. (2012). A mentor development program for clinical translational science faculty leads to sustained, improved confidence in mentoring skills. Clinical and Translational Science, 5(4), 362-367. doi:10.1111/j.1752-8062.2012.00419.x

Fong, D. Y. T, Ho, S. Y., \& Lam, T. H. (2010). Evaluation of internal reliability in the presence of inconsistent responses. Health and Quality of Life Outcomes, 8(27). doi:10.1186/1477-7525-8-27

Fox-Wasylyshyn, S. M., \& El-Masri, M. M. (2005). Handling missing data in selfreport measures. Research in Nursing \& Health, 28, 488-495. doi:10.1002/nur.20100

Gatson Grindel, C., \& Hagerstrom, G. (2009). Nurses nurturing nurses: Outcomes and lessons learned. MedSurg Nursing, 18(3), 183-189.

George, D., \& Mallery, P. (2003). SPSS for Windows step by step: A simple guide and reference. 11.o update (4th ed.). Boston, MA: Allyn \& Bacon.

Hale, R. (2000). To match or mis-match? The dynamics of mentoring as a route to personal and organisational learning. Career Development International, 5(4/5), 223234. doi:10.1108/EUMoooooooo05360

Haynes, R. K., \& Petrosko J. M. (2009). An investigation of mentoring and socialization among law faculty. Mentoring \& Tutoring: Partnership in Learning, 17(1), 41-52. doi:10.1080/13611260802658520

Johnson, B. (2001). Toward a new classification of nonexperimental quantitative research. Educational Researcher, 30(2), 3-13.doi:10.3102/0013189x030002003

Johnson, J. C., William, B., \& Jayadevappa, R. (1999). Mentoring program for minority faculty at the University of Pennsylvania School of Medicine. Academic Medicine, 74(4), 376-379. doi:10.1097/00001888-199904000-00029

Kneipp, S. M., \& McIntosh, M. (2001). Handling missing data in nursing research with multiple imputation. Nursing Research, 5o(6), 384-389. doi:10.1097/00006199200111000-00010

Knowles, M., Horton, E. F., III, \& Swanson, R. A. (2011) The adult learner: The definitive classic in adult education and human resource development (7th ed.). Amsterdam, Netherlands: Elsevier.

Marble, S. G. (2009). Five-step model of professional excellence. Clinical Journal of Oncology Nursing, 13(3), 310-315. doi:10.1188/09.CJON.310-315

Middlebrooks, A. E., \& Haberkorn, J. T. (2009). Implicit leader development: The mentor role as prefatory leadership context. Journal of Leadership Studies, 2(4), 7-22. doi:10.1002/jls.20077 
Palermo, C., Hughes, R., \& McCall, L. (2010). A qualitative evaluation of an Australian public health nutrition workforce development intervention involving mentoring circles. Public Health Nutrition, 14(8), 1458-1465. doi:10.1017/S1368980010002491

Silet, K. A., Asquith, P., \& Fleming, M. F. (2010). A national survey of mentoring programs for KL2 scholars. Clinical and Translational Science, 3(6), 299-304. doi:10.1111/j.1752-8062.2010.00237.x

Smith, W. J., Howard, J. T., \& Harrington, K. V. (2005). Essential formal mentor characteristics and functions in governmental and non-governmental organizations from the program administrator's and the mentor's perspective. Public Personnel Management, 34(1), 31-58.

Streiner, D. L. (2003). Starting at the beginning: An introduction to coefficient alpha and internal consistency. Journal of Personality Assessment, 8o(1), 99-103. doi:10.1207/ S15327752JPA8001_18

Wanberg, C. R., Welsh, E. T., \& Hezlett, S. (2003). Mentoring research: A review and dynamic process model. Research in Personnel and Human Resource Management, 22, 39-124. doi:10.1016/So742-7301(03)22002-8

Wang, S., Tomlinson, E. C., \& Noe, R. A. (2010). The role of mentor trust and protégé internal locus of control in formal mentoring relationships. Journal of Applied Psychology, 95(2), 358-367. doi:10.1037/aoo17663

Zachary, L. J. (2005). Creating a mentoring culture: The organization's guide. San Francisco, CA: Jossey-Bass.

Zachary, L. J. (2010). 8 steps to making an effective mentoring culture. Part 1. Retrieved from http://mentoringexpert.wordpress.com/2010/10/22/8-steps-tomaking-an-effective-mentoring-culture-part-1/

Zellers, D. F., Howard, V. M., \& Barcic, M. A. (2008). Faculty mentoring programs: Reenvisioning rather than reinventing the wheel. Review of Educational Research, 78(3), 552-588. doi:10.3102/0034654308320966

\section{Contact Information}

Lynn Sheridan

Saskatchewan Institute of Applied Science and Technology

sheridan@siast.sk.ca

Lynn Sheridan has been a nursing educator since 1999, was a founding member of the Mentorship Team, and chaired the team until 2010. She has mentored a number of nursing faculties over the years. Her published master's thesis was entitled Integrating Technology and Mentoring for Faculty Development. As program head of the occupational health and safety program, she worked across a multitude of disciplines from student and work-placement perspectives, which led to many additional mentoring opportunities. She has informally evaluated the mentorship culture and now is fortunate to assess it formally with colleagues. 
Natasha Hubbard Murdoch has 10 years of nursing faculty experience and transitioned to the Interprofessional Education Coordinator position. Being a founding member of the Mentorship Team initiated her professional interest in how teams support and mentor each other, and the subsequent perceptions of students and patients. She strives to understand the context of the individual's experience within a group. Her current personal enjoyment is being a student, working on her dissertation topic of interprofessionality as a threshold concept for students working on teams with patients. She is honoured to have worked on this research with her mentor, Lynn.

Emily Harder is currently program head of the Simulation Centres for the province of Saskatchewan. She completed and published a phenomenological study on faculty experiences in a formal mentoring program in a community college setting, as a part of obtaining a master's degree. In addition, Emily has maintained her scholarly knowledge of mentoring via her current position as co-chair of the Mentorship Team, which spans the Schools of Health Sciences and Nursing at Saskatchewan Polytechnic. While involved with the Mentorship Team, Emily has been integral to data collection for ongoing surveys of mentorship within the organization. 